\title{
Socio-Cultural Variables as Indices of Discriminatory Practices in the Workplace: A Sociological Analysis of Employment Relations in Nigeria
}

\author{
Adebisi, Moses Adesola \\ Department of Sociology, Faculty of Social Sciences, \\ University of Ilorin, PMB 1515, llorin, Nigeria. \\ E-mail: masbisi@yahoo.com; mobile: +234(0) 8037147893.
}

\section{Doi:10.5901/ajis.2013.v2n3p477}

\section{Abstract}

The socio-cultural differences observable in the larger political society have been replicated in the workplace to its detriment. Thus, the workplace has been turned into a contested terrain by socio-cultural forces: religion, culture, ethnicity, politics and statism, inter-alia. The influence of these factors on inter-personal and inter-group relations affects the distribution and utility of power as it no longer remains an end in itself but a means to other ends defined by the afore-mentioned narrow-minded variables. This is the crux of the matter. Consequently, the contest for power by various groups along these lines has turned the workplace into an arena of conflicts of various colourations as those who hold power deploy it as an instrument of coercion and for advancing the primordial interests of their kit and kin, group members and supporters to the disadvantage of other groups within the same organization. In such organizations, hard work no longer determines upward mobility such as promotions or appointments. Rather, upward social mobility in terms of career advancement depends on perceived measure of loyalty or group identity by those who expropriate power and its resources within the organization. The paper attempts to x-ray the magnitude of the impact of the subjective application of power for the advancement of group interests; its impact on interpersonal and inter-group relations, morale and productivity, and the distribution of objective rewards such as appointments and promotions, staff training and development; and the conflictual effects on the social structure of the organization in the future based on this negative development that presently pervade and bedevil the workplace in Nigeria, and by implication the developing world in general.

Keywords: Workplace, Discrimination, Socio-cultural Variables, Power, Reward, Statism, Organization, Workplace electronic monitoring.

\section{Introduction}

The workplace, rather than being an arena for the advancement of workers' professionalism, expertise or ingenuity, has become a place for the glorification and promotion of parochial primordial socio-cultural sentiments: religions, cultures, groups, politics, appointments and selective promotions and rewards, and overt executive lawlessness, amongst others. The theoretical works of both classical and contemporary scholars in their various summations alluded to the negative effects of these subjective variables on the objective issues in inter-group relations (Marx, 1848/1948; Weber, 1958; Dahrendorf, 1952; Braverman, 1974; Parsons, 1951; and Parkinson,).

Nigeria, with over 250 federal ministries, departments and parastatals, it is obviously the single largest employer of labour in the country with its labour force in general estimated at about 52.16 million, and ranked the $11^{\text {th }}$ largest by country comparison to the world (World factbook, 2011). Furthermore, the complex nature of its multicultural social structure with over 250 major ethnic groups or classifications make it the single largest multicultural or multi-ethnic country in Africa and one of the largest in the world. Invariably, the conflicts being generated in the multicultural Nigerian society along religious, ethnic or cultural lines are replicated in the inter-group relations among employees in the various workplaces, private or public. Therefore, an adequate appreciation of the nature of workplace conflicts generated largely in this case by the identified socio-cultural variables is made possible by a more than cursory analysis of both symmetrical and asymmetrical theoretical perspectives.

\section{Theoretical Framework}

Marx as a classical scholar argues that the worker under capitalist production systems is under-rewarded by those who control the means of production: the bourgeoisie, who controls the forces of production. Therefore, a man's social status 
is determined by his location along the substructure-superstructure relational axis. Society is to him economic deterministic and the social, political, religious and juridical statuses of men are determined by their economic power (Marx, 1948). The master-servant relationships, established in the post-primitive communal society effectively, according to Marx, bifurcated society into two classes differentiated by their relative economic powers. In the modern societies of today, the pursuit and acquisition of power represents a mean to an end rather the contrary.

This leads us to the proposition of Machiavelli (1992). Nicolo Machiavelli, born in Florence, Italy, in 1469, has generated as much interest as repulsion with the publication of his dissertation on power in 1513. He belonged to the upper echelon of the Florentine bureaucratic institutions. By this position and status, he was connected with some of the most powerful men of power at the time. Consequently, his thesis of power and leadership as presented in The Prince, has been described as "the greatest single study of power on record"(Berle, ). Machiavelli's writings on power have been described for centuries as evil-inspired because of its blatant disregard for morality in the art of management of organizations and societies. Most rulers since Machiavelli overtly or covertly had drawn inspiration and political wisdom from his axioms of power. According to Berle, Machiavellism is described as: "The political doctrine of Machiavelli, which denies the relevance of morality in political affairs and holds that craft and deceit are justified in pursuing and maintaining political power". The methods of the ruler or manager are not the important things but the ends, defined by stability and sustainable or durable hold on power. Machiavelli himself had emphatically stated that "In the actions of men... when there is no court of appeal, one judges by the results"; so the ruler, Machiavelli continues, "must stick to the good so long as he can, but, being compelled by necessity, he must be ready to take the way of the evil". The import of this analysis is to underline the fact that Machiavellian managers employ both tact and deceit as their methods of management by relying on the subjective variables among the workers as means of social control. In Nigeria, religious affiliations, ethnic groups, geo-political variables, and myriads of interest groups are veritable substrates for implementing Machiavellian strategies of power and control of men in the workplace. Conceptualizing workplace politics, the following definitions may suffice for our purpose here. While Bolander (2012) sees (workplace) politics as "the lubricant that oils your organization's internal gears", Lebarre (1999) defines office politics as "simply how power gets worked out on a practical, day-to-day basis".

The politics of the workplace can be very destructive because individuals within the organization will on the platform of the afore-mentioned subjective variables focus more on personal gains or interests rather those of the organization. According to Larsen (2012), "Self-serving political actions can negatively influence our social groupings, cooperation, information sharing, and many other organizational functions".

\section{Nigerian Workplace and Its Political Landscape}

Unlike in the developed countries of the western world, where organizational landscapes are governed by the norms of rationality and the objective application of normative rules, fair application of employment policies, promotions and rewards, the organizational landscapes in Nigeria is filled with political pitfalls, snares and relegation of merits, professionalism and independent mindedness among the workers. In addressing the negative effects of politics on the employees, Berne (2010) states that individuals in organizations must analyze office politics in terms of games. He identifies three types of organizational games: 1).Interpersonal games, which he describes as those games that are played between peers in which they suppress harmful or negative information in other not to upset anybody; 2). Leadership games, which is normally played between supervisors and employees. This type of game is described as "divide and conquer" as the supervisor "sets his employees against each other, with the pay-off that none threaten his power base"; 3). Budget game, where the resources of the organization represent the items of gaming. To address this problem, in terms of the negative effects of organizational politics, Eric Berne, quoting L.A. Witt, of the University of New Orleans, is of the opinion that organizational employees could be protected from the negative effects of organizational politics if their supervisors were able to mold or streamline employee values with theirs. The question that readily comes to the minds of observers of organizational behaviour is that: are the supervisors" ready to make their interests and values amenable to those of their employees, given the fact employees' interests usually run counter to those of the organization when profit and pay are involved?

Therefore, the contradictory interests and value systems extant in the workplace which directly derive from the social values of the larger Nigerian society on the basis of the subjective socio-cultural elements of the population, represent the raison d'être for organizational conflicts, corruption and maladministration. Rather than social institutions and formal organizations being places for the development of credible workforce, ingenuity and professionalism, it has become what Braverman (1974) calls a "contested terrain", where apart from the natural conflict between the forces of capital, there are also the forces of religions, ethnicity and ethnicism, geo-politics, and cultures are in constant opposition 
to each other, thereby tearing apart and chipping away at the edifice of the Nigerian statehood.

\section{The Nature of Workplace Conflicts and Discriminatory Practices in Nigeria}

Inter-group conflicts are commonplace in most organizations, private or public, in Nigeria. The fear of ethnic domination of one group by another is a major reason, whether real or imagined. Political appointments into public offices or employment into government ministries, universities, polytechnics and other institutions of higher learning, parastatals and agencies, are expected by law to reflect the federal character principle with the Federal Character Commission headed by a Director-General as its watchdog. Invariably, the state of origin, i.e. the ethnic group to which the head of the commission or any ministerial head belongs to is important in shaping the employment policies of the concerned organization. Hence, conflicts arising from the methods or criteria deployed in employment exist in various government ministries, departments and parastatals. The same ugliness bedevils the political parties as they bicker over party posts either for self as political godfathers, surrogates or protégés. Many political watchers and commentators are of the opinion that the present political predicaments of Governor Rotimi Amaechi of Rivers State of Nigeria, over his re-election as chairman the Nigerian Governor's Forum, NGF, were not unconnected with his perceived presidential ambition which runs counter the re-election ambition of the incumbent president Dr. Goodluck Jonathan, even though he has yet to publicly declare his intention to run.

The nature of inter-group conflicts in Nigeria can be described as being akin to what Duffy (1995) calls horizontal violence. According to him, "horizontal violence is hostile and aggressive behavior by individual or group members towards another member or groups of members of the larger group". He sees horizontal violence as endemic, destructive and unacceptable within the culture of the workplace. Furthermore, as a non physical form of inter group conflict, it is nevertheless seen as a manifested overt and covert behaviours of hostility (Freire, 1972; Duffy, 1995) and as "a behaviour that is associated with oppressed groups and can occur in any arena where there are unequal power relations, and one group's self-expression and autonomy is controlled by forces with greater prestige, power and status than themselves" (Harcombe, 1999). The competition for power and influence in Nigeria is so serious that power holders often employ any possible method, moral or otherwise to sustain their grip on power. Hence, horizontal violence, which may derive from subtle manipulation of power by those in charge of a system, may be manifested as "conscious or unconscious behaviour"(Taylor,1996), and as "a generally, psychologically, emotionally and spiritually damaging behaviour and can have devastating long term effects on the recipients"(Wilkie, 1996). As a consequence, individuals within the workplace are either forcefully socialized into the dominant values established in the workplace by the rulers in a sullen and helpless way, or reject such values and frustrated out or remain within and fight for legalism and fair play. This is what has been described by a number of authors at various times as "the submissive/aggressive syndrome that results from an internalized self-hatred and low self esteem as a result of being a part of an oppressed group"(Glass, 1997; Roberts 1996 \& McCall 1995).

The nature of competition and conflict within the Nigerian organizational landscape could be manifested also in religious conflicts even at the workplace as well as in the larger political arena as leaders of various organizations and political parties may directly or indirectly instigate their followership into violent confrontations. For instance, the militant organization, Boko Haram, which rejects western education and secular values, became visibly violent in 2009, two years before the 2011 presidential and general elections in Nigeria. After the 2011 vote, the main northern political party, Congress for Political Change, CPC, led by the former head of state, General Mohammadu Buhari, (Rtd), lost the vote to his southern Nigeria opponent of the People's Democratic Party, PDP, Dr. Goodluck Jonathan. Buhari played the victim of an allegedly rigged elected by openly weeping, an action which ignited an orgy of violence against Christians, their property and churches in the northern states of Nigeria. As at today, over 2000 lives, mainly Christian have been lost to the violent campaigns of Boko Haram against a Christian-led federal government. Religious conflicts are sometimes openly evident in the workplaces where open biases in the treatment of some groups on the basis of religion can be openly observed. In these workplaces, the appointment and promotion of staff may be influenced by religious or cultural factors, or the extent to which the organizational powers are satisfied that such workers have been loyal or incorporated into the dominant ideological values imposed on the system by those in control.

\section{Structural Characteristics of Horizontal Violence Observable in the Workplace}

Based on these authors discussed above, Carolyn Hastie outlines the basic features of horizontal violence in the workplace. To her, "All acts of unkindness, discourtesy, sabotage, infighting, lack of cohesiveness, scapegoating and 
criticism" can be regarded as horizontal violence. The following examples are listed as constituting its basic characteristics:

* "Belittling gestures, e.g. deliberate rolling of the eyes, folding of the arms, staring into space when communication is being attempted - body language designed to discomfort the other;

* Verbal abuse including name calling, threatening, intimidating, dismissing, belittling, undermining, humorous 'put downs';

* Gossiping (destructive, negative, nasty talk), talking behind the back, backbiting;

* Sarcastic comments;

* Fault finding (nitpicking) - different to those situations where professional and clinical development is required;

* Ignoring or minimizing another's concerns;

* Slurs and jokes based on race, ethnicity, religion, gender or sexual orientation;

* Sending to 'Coventry', 'freezing out' excluding from activities and conversation, work related and social;

* Comments that devalue:

- People's area of practice;

- Women;

- Others that are different to the 'norm'.

* Disinterest, discouragement and withholding of support;

* Limiting right to free speech;

* Behaviours which seek to control or dominate (power 'over' rather than power 'with');

* Elitist attitudes regarding work area, education, experience etc "better than" attitude;

* Punishing activities by management e.g. repeatedly sending someone out of area; bad roasters; chronic understaffing; lack of concern with the mental, emotional, spiritual and physical health of employees;

* Lack of participation in professional organizations (a subtle form of self-hatred) however, busy family lives can preclude participating in professional organizations". [Carolyn Hastie: Horizontal violence in the workplace: http://www.birthinternational.com/articles/midwifery/69-horizontal-violence-in-the-workplce.html).

Some or almost all of the above techniques are directly observable most public and institutions or establishments in Nigeria. In this age information and communication technology (ICT), electronic monitoring systems such as CCTV circuits for video and audio recording capacities, and other clandestine electronic monitoring devices designed mainly to intimidate, incriminate and subject independent-minded academics or workers to psychological stress or terrorism. A number of technical definitions of what constitutes electronic monitoring with specific reference to the workplace have been provided by some scholars and professional associations:

a) "computerized collection, storage, analysis, and reporting of information about employees' productive activities" (cf: Mishra and Crampton, 1998);

b) "listening to live phone call and recording one's observation" (Riechley, 1996);

c) According to Shostak and Wong, 1999, "electronic mail is becoming as common as the telephone as a workplace tool. But, unfortunately, employees' personal use of the e-mail has resulted in lost worktime and occasional improper use of the e-mail system".

The use of electronic monitoring in the form of mass video surveillance as a psychological tactic designed to manipulate the workers' psyche in industrial organizations has been linked with The Principles of Scientific Management Fredrick Winslow Taylor (1911). As Mishra and Crampton (1998) put it, video surveillance of employees is beneficial..."because it provides an unbiased method of performance evaluation and prevents the interference of a manager's feelings in an employee's review". Other apologists of employees' workplace electronic monitoring listed other benefits which include the following: aiding performance monitoring (Amsler, Findley and Ingram, 2011); better safety, coercing good conduct, theft impediment and rendering proof of any criminal activity in the workplace (Rampur,2001), as a scientific management method (Taylor,1911), and finally, Levine (1999) states that "concealed video surveillance is often the quickest and most cost-effective investigative method available. It provides a good way of documenting evidence that is frequently irrefutable".

On the contrary, a number of experts and practitioners are concerned about ethical issues in terms of violating workers privacy in the of security surveillance at the workplace. eHow.com (2013) Rampur (2011: 3) both agree that video surveillance of employees at the workplace can among other things violate employees' privacy and such violations may be actionable in law and the employer(s) may be charged for invasion of the employees' privacy; decrease in employees' morale which may affect trust level, productivity and of course increased tension in labour-management relations; creating a false sense of security: if not properly or constantly monitored, some of the video surveillance 
systems may not work and a sense of security may pervade the workplace whereas in actual fact, such sense is false. Although employers reserve the right to put in place some security measures to prevent criminality and security breaches and other acts of impropriety, ethical considerations are important in safeguarding privacy, free speech and a psychologically conducive environment for work to take place. In fact, as a result of fear and the need to benefit from the perquisites of loyalty, fellow workers, students and security elements may willingly 'volunteer' to facilitate espionage activities in the workplace, in some cases through outright blackmail depending on the benefits attached. This syndrome thrives well in a multicultural settings such as Nigeria.

\section{Conclusion}

Rewards and benefits in the workplace as shown above depend on primordial relations and the leader's perception of loyalty. Professionalism, expertise and rational thinking no longer command any relevant attention in the Nigerian workplace today. The net result is that elements within the organization are pitched in political and sometimes violent battles of wit in a workplace where the norm of rationality in intergroup relations are expected to have pre-eminent position. In the absence of this, the workplace today is bifurcated along mundane and highly subjective socio-cultural lines that create a scenario of acrimony, conflict and maladministration. The pride, expertise and independence of the workers of the past had been destroyed by the introduction of politics into the management of the workplace where power is exercised on the platform of socio-cultural concerns and definitions inspired by evil philosophies which sees fortune in a metaphorical sense as female which on the principle of libido dominandi (Hobbes, 1985) must be dominated for the sake of domination, or as Machiavelli (1992) puts it brutally, raped for the value of the results. Finally, the future of modern day organizations in Nigeria depends on the courage of corporate Nigeria to exorcize the minutest influence of socio-cultural variables in all aspects of the corporate structure of these organizations and Nigeria as a whole. There is no other path to nationhood and development.

\section{References}

Amsler, Gordon, Findley, Henry and Ingram, Earl. (2011). "Performance Monitoring: Guidance for the Modern Workplace". Supervision. P.16.

Berne, Eric. (2010). Games People Play: The Psychology of Human Relationships. Penguin Books Ltd., ISBN 978-0-14-104027-1

Bolander, Jarie. (2012)."How to Deal With Organizational Politics" http://www.thedailymba.com/2011/02/28/how-to-deal-withorganizational-politics/). The Daily MBA. Retrieved 1 December 2012.

Braverman, Harry. (1974). Labound Monopoly Capital: The Degradation of Work in the Twentieth Century. New York: Monthly Review Press.

Burks, F. (2010). Ethical Issues \& Employee Monitoring of Internet Usage. Chron.com

Dahrendorf, R. (1958). Class and Class Conflict in Industrial Society. London: Routledge.

Duffy, E. (19995). Horizontal Violence: A Conundrum for Nursing. "Collegian". Journal of the Royal College of Nursing. Australia.

Freire, P.(1972). Pedagogy of the Oppressed. England: Penguin Education.

Glass, N. (1997). "Horizontal Violence in Nursing". The Australian Journal of Holistic Nursing. Vol. 4 No. 1.

Harcombe, J.(1999). "Power and Political Power Position in Maternity Care". British Journal of Midwifery. February, Vol. 7 No. 2

Height, Marilyn. (Undated). Office Politics (http://www.bigbadboss.com/office_politics.html), BigBadBoss.com

Hobbes, Thomas. (1985). Leviathan. New York: Penguin Books.

Jackson, Kathryn E. (1998). Designing a Call Monitoring Program. Call Center Operations, p. 97-101.

Larsen, James. (2012). 'Business Psychology - Latest Findings" (http://www.businesspsych.org/articles/209.html).

Larsen, James. (2012). "Organizational Politics" (http:www.businesspsych.org/articles/209.html) Business Psychology. @ Management Resources. Retrieved 1 December 2012.

Lebarre, Polly. (1999). The New Face of Office Politics. (http://www.fastcompany.com/magazine/28/newface.html).

Levine, Barry. (Sep. 1999). The Copper Cape and Other Tales. Security Management [Online], v43 i9 p94(5). Infotrac. Available: http://web1.infotrac.galegroup.com/itw/ .n=48!xrn 2_0_A56212935?

Machiavelli, Nicolo. (1992). The Prince. New York: Dover Püblications, Inc.

Marx, K. and Engels, F. (1848/1948). The Communist Manifesto. London: Electric Book Co.

McCall, E. (1995). "Horizontal Violence in Midwifery: The Continuing Silence". Aims Australia Vol. 3. September.

Mishra, Jitendra M., and Suzanne M. Crompton. (Summer 1998). Employee Monitoring: privacy in the workplace? SAM Advanced Journal [Online], v31 n34 p65 (1). Infotrac. Available: http://web1.infotrac.galegroup.com/itw/ .hasing\&dyn=77!sln_21=0?

Parekh, B. (2000). Rethinking Multiculturalism: Cultural Diversity and Political Theory. Basinstoke: Palgrave Macmillan.

Parsons, T. (1951). The Social System. Glencoe, III.: The Free Press.

Parsons, T. (1951). Towards A General Theory of Action. Mass.: Harvard University Press.

Phipps, Polly A. (Mar.1996). Electronic Monitoring in the Workplace. Monthly Labour Review [Online], v119 n3 p33 (2). Infotrac. 
Available: http://web1.infotrac.galegroup.com/itw/in.dyn=39!xrn_2_0_A18279528?

Privacy Issues at Work. (July 1999). Sales and Marketing Management [Online], v151 i7 p94.Infotrac. Available: http://web1.infotrac.galegroup.com/itw/in.dyn=13!xrn_4_0_A55 072851?

Rampur, Stephen. (2011). Video Surveillance in the Workplace. http://www.buzzle.com/articles/video-surveillance-in-the-workplace.( retrieved 6/4/2013.

Riechley, Kevin R. ( Sep. 1996). World Class Telemarketing Quality Assurance Through Call Monitoring. Direct Marketing [Online], v59 i5 p46.

Roberts, S.J. (1996). "Breaking the Cycle of Oppression: Lessons for Nurse Practitioners? Journal of the American Academy of Nurse Practitioners, Vol. 8 No. 5. May p.209- 214.

Taylor, M. (1996). "An ex-midwife's Reflections on Supervision from a Psychotherapeutic Viewpoint" in Kirkham, M.(ed). Supervision of Midwifes, England: Books for Midwifes.

Weber, M. (1958). The Religion of India. New York; The Free Press.

Wilkie, W. (1996). "Understanding the Behaviour of Victimized People" in McCarthy, P. Sheehan, M. \& Wilkie, W.(eds). Bullying from Backyard to Boardroom, Australia: Millennium Books. 